\title{
MI IDEA DE LA FILOSOFÍA DE VICO. MI EXPERIENCIA DE SU ESTUDIO
}

\author{
Alessia Scognamiglio \\ (ISPF, CNR)
}

RESUMEN: Relato autobiográfico en el que la Autora narra su proceso de formación viquista, a la vez que expone su propia interpretación de lo conquistado en sus estudios de la filosofía de Vico. Un recorrido entre el Derecho universal y la Ciencia nueva, con el hilo rojo de la historia de la Roma antigua.

Palabras Clave: Vico, $350^{\circ}$ Aniversario, Diritto Universale, derecho, historia de Roma, certum-verum, origen de las leyes, A. Scognamiglio.

\section{My conception of Vico's philosophy. My experience of studying it}

ABSTRACT: An autobiographical story in which the Author narrates her Vichian training process, while at the same time she gives her own interpretation of her attainments in her studies of Vico's philosophy. A journey between Universal Law and New Science, with the red thread of the history of ancient Rome.

KeYwords: Vico, $350^{\text {th }}$ Anniversary, Diritto Universale, law, history of Rome, certum-verum, origin of the laws, A. Scognamiglio.

\section{La mia idea della filosofia di Vico. La mia esperienza di studio}

RIASSUNTO: Il presente contributo presenta un racconto autobiografico del processo di formazione vichiana dell'Autrice, esponendo, al tempo stesso, la propria interpretazione e i risultati ottenuti nei suoi studi sulla filosofia di Vico. Un percorso tra Diritto universale e Scienza nuova, in cui emerge il filo rosso della storia dell'antica Roma.

Parole ChiAve: Vico, $350^{\circ}$ Anniversario, Diritto Universale, diritto, storia di Roma, certum-verum, origine delle leggi, A. Scognamiglio.

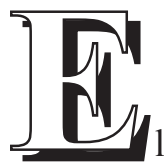

1 encuentro con un pensamiento representa siempre un momento de cambio profundo, de reflexión, de repensar las propias ideas; por eso me gusta pensar, hoy, que precisamente un encuentro, el que tuve con el pensamiento de Giambattista Vico, haya cambiado el curso de mi vida, provocando un cambio de

Este artículo responde a una invitación expresa por parte de la Dirección de la Revista para este volumen especial por el $350^{\circ}$ Aniversario del nacimiento de G. Vico, habiendo superado los criterios de valoración y del proceso de aceptación. 
opinión, una suerte de cortocircuito en el desarrollo de mis estudios, un cambio de ruta que ha modificado profundamente su orientación.

Mi encuentro con Vico y con su pensamiento, más allá de las lecturas escolares y universitarias, se inició en el 2002, año en el que obtuve una beca en el que entonces era el "Centro de Studi Vichiani", y que hoy es el "Istituto per la Storia del Pensiero Filosofico e Scientifico Moderno" (ISPF). Me había licenciado hacía algunos años en letras modernas, y había elegido defender mi tesis en literatura italiana; la historia de la filosofía, en suma, no estaba entre mis principales intereses, pero mi orientación y mi formación eran de impronta filológica, por lo que trabajar sobre textos y reconstruir la escritura original de un autor era algo perfectamente acorde a mis estudios.

El primer contacto que tuve con Vico fue con su pensamiento jurídico, un tema que en este artículo me place retomar y recorrer de nuevo. El derecho, en efecto -como es sabido-, representa un papel central en su sistema filosófico, no solo por cuanto se refiere al ámbito propiamente jurídico, sino también por cuanto concierne a la idea que, dentro de la especulación viquiana, asume la historia, entendida tanto en la acepción de "historias que transcurren en el tiempo", como en la de "historia ideal eterna". El derecho, además, dentro de dicho sistema, aparece como una categoría compleja, que refleja las condiciones generales de lucha de todos contra todos, a partir de la cual tienden progresivamente a crearse y a generarse relaciones sociales de dominio y de subordinación, a causa de las cuales la violencia abierta y la lucha generalizada son sustituidas lenta y parcialmente por las relaciones de protección. El combate social y el contraste entre las clases -considerado por Platón y por Aristóteles como una grave amenaza para la supervivencia del Estado, pero ya señalado como algo positivo por Maquiavelo- asumen de hecho para Vico un valor totalmente positivo, y se consideran el único principio dinámico apto para promover cualquier desarrollo social e histórico, además de legislativo y consuetudinario. Y así, antes de la luminosa visión de la Scienza nuova, a partir del Diritto Universale, pero bajo ciertos aspectos incluso antes en el De Ratione, ${ }^{1}$ la reflexión de Vico en torno al derecho en general, y en lo específico en torno a las leyes, a las instituciones jurídicas y al derecho romano constituye una vía de ingreso privilegia-

1. G. Vico, De nostri temporis studiorum ratione [1709], en ID., Opere, 2 vols., edición de A. BATTISTINI, Milán, 1990, vol. I; de ahora en delante De rat. [N.E.- Existe trad. española: G. VICO, Obras. Oraciones inaugurales \& La antiquísima sabiduría de los italianos, pres. de E. Hidalgo-Serna, introd. de J.M. Sevilla, ed., trad. del latín y notas de F.J. NAVARro GómEZ, Anthropos, Barcelona, 2002]. Vico dedica a la más importante de las adiumenta de la ratio studiorum, la iuris prudentia, el amplio capítulo XI del De rat., en el cual anticipa temas y análisis destinados a encontrar un más completo desarrollo además de en el Diritto Universale y en la Scienza nuova, también en el Ragionamento d'intorno alla legge delle XII Tavole venuta da fuori in Roma. Tal escrito fue elaborado con ocasión de las así llamadas Correzioni, Miglioramenti e Aggiunte "terceras", sucesivas a la infeliz publicación de la Scienza nuova de 1730, fue luego inspiración para la edición de 1744. 
da para la comprensión del principio del verum factum y de la "historia ideal eterna", si bien es verdad que también la cuestión del significado atribuible a la transformación de las instituciones histórico-jurídicas puede considerarse en el origen del sistema especulativo del filósofo napolitano.

El motivo del desarrollo socio-cultural, en efecto, alcanza -es verdad- en la Scienza nuova un horizonte problemático mucho más amplio respecto al propuesto en el Diritto Universale, pero en su interior los resultados de la reflexión respecto a la historia romana, sobre sus instituciones jurídico-políticas, sobre el lenguaje arcaico de las leyes, sobre el conflicto social, por cuanto modificados en una obra que presenta un nuevo y más amplio plano temático, tienden sustancialmente a confluir y a reproponerse. Es por esto por lo que propondré, en esta breve nota, dilucidar cómo el derecho inmediatamente es instituido por Vico también como una expresión de la lucha entre utilidades contrastantes y, por tanto, de la lucha eterna, aunque varía en el tiempo, entre individuos y grupos sociales, a la luz del común intento que creo que mueve el Diritto Universale y la Scienza nuova, que es el de probar cómo el derecho se sustituye a la fuerza en la medida en la cual el Estado se afirma como conjugación de una consciencia moral.

En el seno del problema de la fundación jurídica del Estado Vico se sitúa, en efecto, en aquella fase de transición que empieza a partir de la crisis del iusnaturalismo de Grocio para encaminarse hacia la estructuración del formalismo jurídico kantiano y post-kantiano. El encuentro con Grocio y con el iusnaturalismo señalan plenamente, desde el principio, la introducción en la exégesis viquiana de la reflexión -más allá del hecho moral y jurídico- sobre el tema de la necesidad de una ley capaz de regular el combate entre las clases y la violencia política, con el fin de afrontar el problema del mal, de la naturaleza bestial, de la caída del hombre de los orígenes; la gran cuestión, en suma, del pecado, de la redención, de la gracia, de la Providencia.

Creo, en efecto, que para Vico es precisamente el desencuentro entre intereses y utilidades antitéticas lo que transforma las instituciones políticas, sociales y jurídicas, es decir, lo que garantiza a la realidad del derecho vitalidad y desarro1lo, "curso" y "despliegue". Entendida en tal sentido, en efecto, la lucha social por el derecho aparece verdaderamente como el motor de la realidad jurídica, la razón verdadera de su génesis, de su comenzar, de su hacerse y de su histórico mutar. Y es por esto por lo que sostengo que es necesario aludir al profundo y apasionado, aunque a menudo históricamente no del todo atendible, análisis que Vico hace de la historia de la Roma antigua, y a la sustancia de esta historia, que creo que debe incluirse en la lucha político-social, además de económico-jurídica, entre el patriciado y la plebe.

Sin embargo, la división de las épocas que Vico propone -teocracia de los padres de familia, teocracia "extendida", comprendiendo la clientela, república de 
los optimates integrada en el senado por las «gentes menores», república popular o mejor "monarquía popular" porque está constituida por «reinos simples», y finalmente la época en la cual «introducidas las guerras, toda la autoridad del género humano retorna a Dios» ${ }^{2}$ - está motivada por el impulso que generan las relaciones sociales y económicas, visto que el complejo de tal fenómeno sufre la interferencia de lo que él llama circulus. La verdadera clave de esta periodización es la historia romana, es decir, el desencuentro entre la custodia del derecho privado por parte de los patricios y la contemporánea, violento impulso hacia la equidad natural por parte de la plebe. El cambio de las formas políticas, por tanto, es entendido por el filósofo napolitano también como mutación económica y social, en cuanto que, si por un lado todo tiende a hacer desaparecer la efectiva propiedad fundacional de los no-cultivadores a través de la transformación del dominio "bonitario" de los campos en "quiritario", y luego a través de la sucesiva formalización de este último en "eminente", por otro lado determina la extensión de los derechos civiles, que a su vez comporta el desarrollo de la democracia en el ámbito de la república romana.

Es por esto -intuye Vico- por lo que mientras el patriciado permanece sólidamente anclado a los propios intereses constituidos y protegidos normativamente y está formado por los padres, que hacen legítimos matrimonios y auspicios, la plebe, compuesta por fámulos y clientes, sin matrimonios ni auspicios, reclama y progresivamente adquiere el dominio quiritario de los campos, la ley escrita, el derecho de los casados, los connubia patrum, es decir, el derecho de contraer matrimonios solemnes, y -en consecuencia- la conquista del derecho de ciudadanía. Con el aumento cada vez mayor de los fámulos y de los clientes y de la progresiva decadencia, por parte de los nobles, de la honestidad y de la austeridad, se inician las «contiendas heroicas», y después de que el primer estado proscrito reemplaza al social, gracias al afirmarse de la vida sedentaria-agrícola, en él germinan los trazos culturales de una formación social-arcaica: posesión familiar de la tierra, religión de los auspicios, ius divino no escrito. La distinción entre «héroes»-detentadores de la propiedad y del arcano del derecho-y «fámulos»-subordinados económica y jurídicamente- no garantiza ningún equilibrio y conduce rápidamente a la sublevación de los siervos, presagio de la constitución jurídico-política del Estado. Cuando los fámulos,

2. Para el Diritto Universale se utiliza la edición dirigida por P. Cristofolini (G. VICO, Opere giuridiche, editada por P. CRistofolinI, intr. de N. Badaloni, Florencia, 1974), que comprende la Sinopsi del Diritto universale (1720) [= Sin.], el De universi iuris uno principio et fine uno (1720) [= De uno], el De constantia iurisprudentis (1721-1722) [= De const.], las Notae in duos libros (1722) [= Notae] y las Dissertationes. De ahora en adelante se citará por esta edición abreviando con la sigla $O G$, indicando entre corchetes las obras a las cuales se reenvía cada vez y las referencias relativas a los capítulos y a los parágrafos viquianos, señalando los primeros con números romanos y los segundos con números árabes. Para el De Uno la traducción del latín de C. Sachi (Milán, 1866), conducida sobre la edición Ferrari (Milán, 1852) y utilizada por la edición Cristofolini ha sido modificada donde ha parecido necesario. OG, p. 658 [De cost., § XXX]. [N.E.- Existe trad. esp.: G. VICO, Obras III. El Derecho Universal, pres. E. Hidalgo-Serna y J.M. Sevilla, ed., trad. del latín, introd. y n. de F.J. NAVARro GómEZ, Anthropos, Barcelona, 2009]. 
gradualmente, dejan de creer en su neta separación de naturaleza con los nobles, considerados antes héroes por ellos, hijos de los dioses, se alían contra los nobles, los cuales para intentar defenderse se unen dando vida a los senados heroicos.

Para Vico, pues, la primera forma de coexistencia político-jurídica, de convivencia social, son las repúblicas aristocráticas, los reyes aristócratas, o sea, los padres en los Senados heroicos. El derecho se entiende como prerrogativa de los nobles no en virtud del arbitrio de estos, sino porque ha sido dictado por los auspicios, que son exclusivos de los nobles. Esta es la edad de la jurisprudencia rigurosa y rígida, en la cual la ley domina por su certeza, o sea, por el sonido inequívoco de las fórmulas en que se expresa. En dicha edad no existe aún interpretación jurídica, en cuanto que las mentes de los hombres, todavía rudas, no son capaces de aprehender el espíritu de las leyes: por eso los pactos, antes de ser cumplidos con el solo consenso, reclaman "el acto concreto", el ejercicio corpóreo de darse la mano. Solo más tarde será suficiente la imitación de dichos actos, de donde los modos solemnes del contrato, las máscaras y el individuo jurídico, en sustitución de la cosa y de la persona. De ahí el formalismo de las antiguas jurisprudencias, definidas por Vico en la Scienza nuova como «serio poema» y «severa poesía». ${ }^{3}$ Con las luchas heroicas los plebeyos conquistan paulatinamente la participación en la religión y en los matrimonios solemnes, con la consecuencia de que viene progresivamente a menos la diferencia con los padres. La república aristocrática se convierte en república democrática o popular, y a la edad poética -de los héroes- sustituye la edad de los hombres, de la razón «totalmente desplegada», y de estas repúblicas populares derivarán las leyes y de las leyes la filosofía. El poder político ya no está exclusivamente en manos de los nobles y ya no se fundamenta en la separación de naturalezas, sino que se basa en la distinción de mérito y de riqueza y es esencial para todos.

He aquí que, por tanto, objeto del De Uno es, junto al despliegue de la historia de Roma, la reconstrucción del desenvolvimiento histórico del derecho, el problema de la historia del derecho en general, y en particular del derecho romano, en el que Vico intuye la coexistencia de los dos derechos antitéticos, el derecho civil y el pretorial, de los cuales el primero nace de la autoridad y el segundo de la razón, el uno se fundamenta en el certum y el otro en el verum. Es aquí donde el filósofo napolitano comienza a intuir que puede existir un vínculo entre certum -historia jurídica- y verum -derecho natural-. En el De Uno, ${ }^{4}$ relacionando derecho natural, costumbres y leyes, Vico afirma que tanto mores como leyes no son más que interpretaciones del derecho natural. Ahora la contribución aportada por Vico al análisis realizado en época moderna de la función legislativa de la plebe y del valor de los plebiscitos como fuente "posi-

3. G. VIco, Principj di scienza nuova d'intorno alla comune natura delle nazioni [1744], en ID., Opere, op. cit., vol. I, $\S 1.037$, p. 926.

4. $O G$, cit., p. 174 [De uno, § CXLIII]. 
tiva" y casi exclusiva del derecho privado es fundamental, visto que, como se lee en el De Uno, «ex hoc ipso iure civili communi est celebre jus quiritium romanorum». ${ }^{\mathbf{5}}$

En el Diritto Universale -que intenta también trazar una teoría general del derecho y del Estado- el filósofo delinea una historia del derecho romano. Según Vico, en los orígenes del derecho romano intervienen dos fuentes, que están en la base de cualquier disciplina jurídica: estas son la costumbre y la ley, ambas interpretaciones del derecho natural. La preeminencia de la costumbre sobre la ley es valientemente defendida en los estados de pura aristocracia, que están en los orígenes de toda organización política. La ley nace lentamente, con la evocación en los casos singulares del mos maiorum: los decretos del príncipe, que habían sido previamente suministrados para una determinada ocasión, eran entonces asumidos a guisa de ejemplo, y por tanto extendidos sucesivamente a todos los casos similares. Entre las etimologías del término $l e y^{6}$ Vico -haciendo derivar esa palabra ley de un antiguo ius 《secreto» ${ }^{7}$ - prefiere sin duda aquella que deduce el lema de legere o sea "discernir", en cuanto que - a la luz de algunos aspectos- la ley puede parecer una selección de todo lo que es conveniente a los hechos presentes. Sobre esta base, costumbres y leyes irán adquiriendo un amplio y, sobre todo, paralelo desarrollo. Sin embargo, aunque ambas eran la expresión del derecho, solo las costumbres han sido su interpretación más firme y más sólida -firmior, dice Vico- ya que ellas han sido demostradas desde siempre mediante los hechos, mientras que las leyes, incluso siendo interpretaciones de ellos «quandoque melior, et semper infirmior», siempre son «a mutabili voluntate dictatae». ${ }^{8}$ Es por esto, pues, por lo que los gobiernos aristocráticos y los monárquicos resultan ser los más estables, como demuestran precisamente los casos del gobierno de Esparta y, en época "moderna", de la República veneciana. Las repúblicas populares, al contrario, son para Vico «gobiernos $[\ldots]$ siempre poco duraderos y muy turbulentos», como prueban las experiencias políticas de Atenas y de Roma. Eso no excluye, naturalmente, que también en las repúblicas populares cada cosa haya sido ordenada con verdaderas y propias leyes, que siempre han expresado la voluntad del pueblo.

En la ley, por consiguiente, Vico descubre y aprecia un elemento de progreso, en cuanto que la disciplina de las relaciones sociales, que tiene lugar a través de la ley misma, «es de todas la más pensada, por ser de agudo y perspicaz ingenio el entender los géneros de las cosas, de lo que son expresión las leyes propiamente dichas». ${ }^{9}$ En la historia de la Roma republicana -intuye Vico- emerge la sustancial prevalencia de la ley sobre la costumbre: la lucha entre patricios y plebeyos, que

5. Ibíd., p. 143 [De uno, § CXXIII].

6. Ibíd., p. 185 [De uno, § CXLIX, 1].

7. Ibídem.

8. Ibíd., p. 175, 177 [De uno, § CXLIII].

9. Ibíd., p. 177 [De uno, § CXLIV, 1], pero también pp. 167, 169 [De uno, § CXXXVIII, 1-9]. 
caracteriza ese periodo histórico, culmina en el advenimiento de las leyes de Publio Filón, de las cuales el resultado más relevante fue la equiparación en eficacia legislativa de las peticiones de los concilios de la plebe, es decir, de los plebiscitos, con los decretos del Senado. ${ }^{10}$ Surgió, como consecuencia, una legislación de los tribunos favorable a las razones del pueblo, ${ }^{11}$ y la actividad del Senado resultó disminuida y restringida al ámbito único del derecho público. ${ }^{12} \mathrm{El}$ derecho privado -fundado en la costumbre- pasó así a manos de los patricios, los cuales de autores pasaron a ser custodios, afanándose, más allá de mantener secreta, "arcana" la ciencia del derecho, en hacer además que el derecho constituido fuese observado en los "juicios privados". En esta tarea de custodia del derecho privado consuetudinario - gracias a la cual la tradición consuetudinaria permaneció aún viva junto a la producción legislativa- los patricios se sirvieron del edicto del pretor, y de la elaboración de la jurisprudencia. El pretor romano administra a los juicios las fórmulas sobre las que ellos mismos deben fundamentar sus sentencias; de tal modo él proveía a la tutela del derecho consuetudinario, y con el mismo intento intervenía en variados actos de la vida legal: su función era, por consiguiente, la de custos civilis iuris ${ }^{13}$ La jurisprudencia, por el contrario, dirigida a la interpretación y a la aplicación del derecho, se reservaba -desde el inicio- a la clase de los optimates.

Ahora está bien reflejar cómo la especulación viquiana tiende a localizar, en el seno del De Uno, una razón intrínseca apta para justificar tal atribución exclusiva. ${ }^{14}$ Las primeras leyes tenían siempre, en efecto, un carácter divino: estas -señala Vicono nacieron por efecto de "impostura" - porque ese actuar no habría podido nunca acordarse con el estado de infancia del género humano- sino que se alumbraron precisamente gracias a un "espíritu de religión". ${ }^{15} \mathrm{He}$ aquí por qué resultó necesario, además de confiar la ciencia de las leyes a los optimates, ${ }^{16}$ también ingeniárselas para que esta permaneciera en secreto para los clientes como hombres nuevos. En la Roma republicana los patricios, habiendo ya dejado de constituir un orden separado, no encontraron otro medio para conservar la propia preeminencia sino el de mantener en secreto el conocimiento de la razón civil. ${ }^{17} \mathrm{La}$ ciencia jurídica poseída por los optimates se extendía al triple derecho sacro, público y privado; en tal sentido la jurisprudencia abrazaba el conocimiento de las cosas divinas y humanas. El derecho divino era fuente del derecho humano, su conocimiento se dio a conocer únicamente a quienes formaban parte de los colegios de los pontífices y de los augures, y ya que a

10. Ibíd., pp. 223, 225 [De uno, § CLXI, 1-7].

11. Ibíd., pp. 227, 229 [De uno, § CLXIII, 1-4].

12. Ibíd., pp. 229, 231 [De uno, § CLXIV, 1-2].

13. Ibíd., pp. 231, 233 [De uno, § CLXVI, 1].

14. Ibíd., pp. 233, 235 [De uno § CLXVII, 1-3].

15. Ibíd., pp. 235, 237 [De uno § CLXVIII].

16. Ibíd., pp. 237, 239 [De uno § CLXIX, 1-8].

17. Ibíd., pp. 243-249 [De uno § CLXXI, 1-9]. 
dichos colegios se agregaban solamente los hombres de sangre noble, de ello se derivó que solamente a los patricios pudo ser revelada la ciencia del derecho privado. De ahí que Vico entonces demuestre la gran importancia que en Roma, en el desarrollo del derecho privado, está reservada -también durante el periodo republicano-a todas aquellas fuerzas que provienen, sobre las trazas de la tradición, de la práctica elaboración de la magistratura y de la jurisprudencia. Un punto de notable importancia está en determinar qué materias en la tradición constitucional de Roma se reservan a las actividades de los dos órganos legislativos en el periodo republicano, es decir, al Senado y al concilio tributo de la plebe. De ahí se sigue que, si el derecho privado tenía una base prevalentemente tradicional, el Senado y el concilio tributo de la plebe se ocuparon principalmente del derecho público. Todas las veces en las que, también en el periodo republicano, se llegó -aunque por vía excepcional- a peticiones de derecho privado, dichas peticiones fueron de competencia exclusiva de los concilios de la plebe sobre propuesta de los tribunos: es decir, fueron plebiscitos. Así, todas las leyes de derecho privado, en el periodo republicano, fueron de iniciativa tribunicia, o sea, plebiscitos dotados de caracteres excepcionales respecto al ordenamiento jurídico existente. El derecho de Roma - esto emerge claramente- se forma a través del conflicto entre patricios y plebeyos, y solo en la comprensión de esta dramática contraposición de fuerzas reside la "clave de toda la historia romana". A partir de un conflicto de tal suerte surge un nuevo derecho, que une dos elementos importantes: el elemento tradicional, del cual son custodios los patricios, y las nuevas necesidades de la vida social, de las cuales son representantes las clases populares. ${ }^{18}$ El gran mérito de la Roma antigua reside en haber sabido conciliar la custodia de la razón con la libertad de enmendar las leyes. De esta síntesis, en efecto, no nació un Estado clasista, sino una república democrática, donde patricios y plebeyos se convierten en elementos concordantes y necesarios para la misma finalidad histórica: de su progresivo acercamiento surge ese orden jurídico basado en la equidad natural.

$\mathrm{Y}$ es a partir de esta rápida alusión a un problema tan fuerte como este del nacimiento de las leyes y de las costumbres jurídicas como se puede -a mi entender-comprender bien cuál es la extraordinaria importancia de esta intuición viquiana, desde la cual es posible también reconocer en el pensamiento de Vico una primera alusión a la teoría de las clases sociales, además de ver en Vico mismo a uno de los primeros pensadores capaces de comprender el sentido profundo de la lucha por el derecho como lucha de clases.

[Traducción del italiano por María José Rebollo Espinosa]

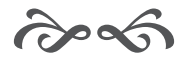

18. Ibíd., pp. 273, 275; 281, 283; 289 [De uno §§ CLXXXIV, 1-2; CLXXXVI, 1-2; CLXXXIX]. 